\title{
Dificuldades do ensino e da aprendizagem das Ciências no Século XX, desafios para os professores do Século XXI
}

\section{Resumo}

Configuram-se no presente texto algumas das principais dificuldades sempre presentes no Ensino de Ciências neste século, as quais advieram da manutenção - principalmente em âmbito escolar - de concepções assumidas no século XIX, que se tornaram tão resistentes pelo uso acrítico reiterado, que retardaram a compreensão dos avanços do conhecimento científico no curso do processo de ensino e de aprendizagem de Ciências. Tais concepções influíram, certamente, para o cultivo de UM ÚNICO MÉTODO CIENTÍFICO dotado de atributos supostamente rigorosos e verdadeiros, calcados na isenção do sujeito, na neutralidade da ciência, e em aspectos predominantemente quantitativos na abordagem de fatos ditos científicos, com base exclusivamente na comprovação de hipóteses em função da empiria. A visão de um sujeito isento/neutro e de uma ciência externa/neutra/quantitativa/ empírica cultivou, ainda, dissociações de idéias que constituíram dicotomias, as quais, por sua vez, se tornaram características do século $\mathrm{XX}$, tais como conteúdo-forma, teoria-prática, e que geraram, em contextos como o nosso, outras dicotomias, dentre as quais a referente ao pedagógico-específico na consideração do conhecimento/conteúdo de ensino, no curso da formação de professores e da abordagem/do desenvolvimento de processos de ensino. As abordagens de cada comunicação especificam pontos e contrapontos de várias dessas relações cognitivas, de forma a ensejar o estabelecimento de relações compreensivas - tanto pela abrangência quanto pelo entendimento - de concepções, metodologias e abordagens do conhecimento científico a partir deste ano 2000, constituindo desafios para os Professores das Ciências no curso do século XXI.

\begin{abstract}
This text intends to discuss some of main difficulties which are always present in the Sciences teaching at this time, inside school environment, principally-proceeding from conceptions used on century XIX that became so much resistant because were adopted by an uncritical way. Those conceptions have retarded the understanding of scientific knowledge advances through the Sciences teaching learning process. Those conceptions have also influenced the culture of AN UNIQUE SCIENTIFIC METHOD, with suppositively rigorous and truthful attributes, based on the subject exemption, on the neutrality of the Science and, overall, on quantitative aspects in the approaches of facts as scientific supported, exclusively on empirical hypothesis approbation. The point of view of an exempt/neutral subject as well of an external/ neutral/ quantitative/ empirical Science, has yet cultured ideas dissociations that have constituted dichotomies, which, by its time, have became characteristics of century $X X$ as form-content, theory-practice and so on. Others dichotomies also have been generated in the educational contexts as those ones referring to pedagogicspecific knowledge-teaching content in the teacher's formation process and of teaching process develop-
\end{abstract}

\footnotetext{
*Doutorando em Educação do PPGE/UNIMEP e professor das Faculdades Integradas "Campos Salles". O presente trabalho foi desenvolvido no núcleo de Estudos em Educação em Ciências sob a orientação da Dra. Rosália M. Aragão e participação dos doutorandos : Heloisa Helena Oliveira, Lenir B. Zanon, Mara S. Cesário da Mota e Raquel C.D. Grecchi.
} 
ment approach. The deal of each communication specifying points and counterpoints of several cognitive relationships in order to give an opportunity for settling up comprehensive and understanding relationships of conceptions, methodologies and scientific knowledge approaches since this year of 2000 , that are challenges for teachers in the science area through century XXI.

\section{Introdução: considerando os múlti- plos saberes da Ciência no ensinar e no aprender}

A cada vez que leio ILYA PRIGOGINE, não posso deixar de me sentir envolvido por uma visão da Ciência que ele não só nos deixa entrever, mas nos afirma surgir no último terço deste século XX. Ao tempo do meu entusiasmo, sentimentos conflitivos de incerteza me possuem, quando lanço pensamentos de professor para a nossa escola brasileira - que nesses termos não se apresenta tão diferente das escolas do mundo - e lamento profundamente a perdição histórica em que ela se encontra, especialmente em relação ao ensino de ciências, por permanecer no reino da obsolescência e da mesmice. Vale a pena transcrever PRIGOGINE (1996:11), quando diz, por exemplo: ... ao longo das últimas décadas, nasceu uma nova ciência, a física dos processos de não-equilíbrio. Esta ciência levou a conceitos novos como a auto-organização e as estruturas dissipativas, que são hoje amplamente utilizadas em áreas que vão da cosmologia até a ecologia e as ciências sociais, passando pela química e pela biologia.

De forma clara, Prigogine afirma que, sem a coerência dos processos de não-equilíbrio, o aparecimento da vida na Terra seria inconcebível. Isto porque, no âmbito de uma concepção de ciência-verdade, de ciência-imutável-inquestionável, que ainda hoje se mantém com exclusividade, alguns aspectos acham-se 'congelados há séculos', exatamente aqueles atinentes à ciência clássica que privilegiava a ordem, a estabilidade (a regularidade). Hoje, em outros ter- mos, na perspectiva dessa nova (outra!) ciência, em qualquer nível de observação, passa a ser reconhecido o papel primordial das flutuações e da instabilidade. Associadas a essas noções, aparecem também as escolhas múltiplas e os horizontes de previsibilidade limitada. Além disso, noções como a de caos tornaram-se populares e invadem todos os campos da ciência, da cosmologia à economia. Nesse âmbito, pode-se dizer que, desde que a instabilidade é incorporada, a significação das leis da natureza - cerne do paradigma da ciência moderna - ganha um novo (outro!) sentido, posto que essas leis passam a exprimir possibilidades . Vale reiterar com Prigogine que, tanto na dinâmica clássica quanto na física quântica, as leis fundamentais exprimem agora possibilidades e não mais certezas. Reconhece-se, assim, que não há só lei, mas também eventos que não são dedutíveis de leis, mas atualizam as suas possibilidades. No dizer de PRIGOGINE (1996:14)... pensamos situar-nos hoje ... no ponto de partida de uma nova racionalidade que não mais identifica ciência e certeza, probabilidade e ignorância.(...) Assistimos ao surgimento de uma ciência que não mais se limita a situações simplificadas, idealizadas, mas nos põe diante da complexidade do mundo real, uma ciência que permite que se viva a criatividade humana, como a expressão singular de um traço fundamental comum a todos os níveis da natureza. Temos sido, assim, convidados a participar de uma excursão por uma ciência em evolução, ultrapassando os limites de um conhecimento ideal que alcança a certeza e que - restritivamente - se manifesta onipresente nas abordagens escolares.

No ensino e na aprendizagem das ciências ao nível escolar, "uma vez que as condições iniciais sejam dadas, tudo é determinado". Nessa perspectiva, a natureza é um autômato que podemos controlar, pelo menos em princípio. A novidade, a escolha, a atividade espontânea são apenas aparências, relativas apenas ao ponto de vista humano (PRIGOGINE, 1996:20). Esta é uma pálida idéia, ou uma caricatura, que lembra bem a figura da ciência que é usualmente aborda- 
da/tratada na escola. Certamente se expressa uma concepção de ciência não mais consentânea com o nosso contexto histórico do presente. Situa-se tal concepção no âmbito de um paradigma agora claramente decadente, contudo, no curso da escolaridade, pouco ou nada se tem feito para configurar outras (novas?) idéias de ciência que possam configurar, por sua vez, um outro paradigma emergente, tendo em vista uma concepção de ciência do ano 2000, ou melhor, uma concepção de ciência do século XXI, uma vez que, mantendo-se o ensino e a aprendizagem em termos reprodutivistas-memorísticos de informações descontextualizadas das ciências, onde se abriria ainda agora, neste tempo que nos resta, um espaço para discussão escolar, para troca/ampliação de idéias de Ciência ?

Para tanto, uma série de dificuldades sempre presentes no contexto escolar decididamente precisariam ser enfrentadas, entre as quais as relativas ao cultivo de UM ÚNICO MÉTODO CIENTÍfICO no Ensino de Ciências. Tais dificuldades se imbricam, claramente, a obstáculos epistemológicos que impedem a superação da idéia de "um único verdadeiro método científico que sempre foi assim", porque implicam, por sua vez, tanto concepções ultrapassadas de ciência quanto percepções de atributos estáticos e pseudocientíficos do método único, mantidos sob a influência do positivismo e do positivismo lógico. Ao se cultivarem esses aspectos de unicidade, cultiva-se, ao mesmo tempo, não só uma ciência externa ao sujeito que passivamente é tido e previsto para absorver idéias ditas científicas, mas também a própria descaracterização desse sujeito submetido a um processo constante de "des-a-sujeitação".

Nesse âmbito, destacam-se, também, as questões/relações que podem ser postas/estabelecidas como concernentes à concepção de um sujeito isento/neutro e à visão restrita de uma ciência externa/neutra/quantitativa/empírica como geradora e agente do cultivo de dissociações de idéias que constituíram/constituem as dicotomias características deste século XX, dentre as quais conteúdo-forma, teoria-prática, e que geraram, por sua vez, em contextos como o nosso, outras dicotomias ou dualismos, dentre os quais a dicotomia pedagógico-específico na consideração do conhecimento/conteúdo de ensino no curso da formação de professores e da abordagem do desenvolvimento de processos de ensino. Nessa perspectiva, abordam-se as questões atinentes à imbricação teórica-metodológicaepistemológica, numa relação triádica de inclusividade para superação de dicotomias que implica a consideração do "terceiro excluído". Afinal, a consideração da complexidade do real no ensinar e no aprender - expressa-se claramente na assunção dessa luta pelo terceiro excluído.

\section{Compreendendo uma concepção de Ciência do ano 2000...}

As pesquisas educacionais, que vêm sendo desenvolvidas sobre os processos de ensino e de aprendizagem para aquisição de conhecimento específico das Ciências, dão conta de que se encontram, nos contextos usuais de sala de aula, formas diferenciadas de ensino tradicional, configuradas em função do estilo cognitivo de cada professor (ARAGÃO, 1993). Nessa perspectiva, restringem-se mais as dúvidas de que a prática pedagógica de cada professor manifesta as suas concepções de ensino, de aprendizagem e de conhecimento/ciência, como também as suas crenças, seus sentimentos, seus compromissos políticos e sociais. (Idem, p.9) Contudo, as concepções usualmente manifestas por docentes advêm da manutenção, principalmente em decorrência de sua formação, de concepções historicamente descontextualizadas, assumidas em grande parte ainda no século XIX e que se tornaram cada vez mais resistentes - pelo uso acrítico reiterado - influindo para retardar a compreensão dos avanços do conhecimento científico no curso do processo de ensino e de aprendizagem das Ciências.

Os aspectos que estão nitidamente presentes nas práticas pedagógicas das aulas de Ciências 
(Física, Química, Biologia, dentre outras) são referentes a :

A) Descompassos entre idéias presentes nos discursos de exposição ou de transmissão de conteúdos, e a consideração prática ou operacional dessas mesmas idéias nos processos pedagógicos desenvolvidos por professores.

Muito embora, nos dias de hoje, ao nível escolar, pode-se dizer, não mais se confrontem proposições que assentam dogmaticamente uma visão de ciência neutra, continua-se a primar pela insistência na visão da ciência verdadeira, de forma tal que a meta do saber escolar tem sido apresentar e tratar do conhecimento considerado neste âmbito, o conhecimento científico verdadeiro e único. Tais idéias são advindas do positivismo, do positivismo lógico e do empirismo no ensino, principalmente em razão dos aspectos relativos à concepção de conhecimento que se tem cultivado na escola como "um conjunto de dados e informações passíveis de absorção pelo aluno". Nesse sentido, o conhecimento, como ciência, é concebido em termos de uma verdade universal que permanece como uma espécie de correspondência termo a termo da forma como o mundo é e funciona (LAKATOS,1970). Assume-se o paradigma das ciências naturais e permanece-se no âmbito deste paradigma que favoreceu, certamente, a visão de ciência moderna (a partir do século XVII) que passava a exigir isenção do sujeito que aprende ciência ou que lida com o que é considerado científico, quase nos mesmos termos postos, ainda hoje, nas escolas. Tal visão externa de Ciência apresenta-se dissociada do sujeito (CHALMERS, 1993) e é reiterada, no curso da formação docente, quer pedagógica quer científica, por um tipo de racionalidade restrita à técnica, ao invés de dizer respeito à compreensão de atividades e/ou de processos ditos científicos. Em função disso tudo, os contrapontos que foram surgindo de novas e outras visões sobre a Ciência, e sobre fenômenos que se situem no âmbito das ciências, em contextos sócio-históricos mais atuais, deixaram de merecer consideração ao nível escolar, porque implicaram (implicam!) um outro tipo de controle - advindo de uma mudança de paradigma que passava a conceber a Ciência como produção cultural do homem - que não era passível nem de compreensão nem de discernimento imediatos, principalmente por parte de professores dogmáticos, tradicionais, tidos como rigorosos (portanto 'científicos') em relação ao que deve ser aprendido pelos alunos.

B) Novas e outras concepções surgidas em relação à visão de Ciência suscitaram novas e outras posições da filosofia da ciência contemporânea, que tem se preocupado em explicitar como as concepções científicas são adquiridas e como essas concepçóes mudam, enfatizando o papel das concepções processuais estabelecidas, na aquisição e na produção de novos conhecimentos.

A concepção obsoleta de ciência verdadeira e inquestionável permaneceu/permanece na escola sem que, ao nível docente, se possa chegar a admitir qualquer perspectiva de mudança de ponto de vista, de admissão de outra concepção. Tal posição dominante ocasiona malefícios, posto que, no curso do processo de ensino e de aprendizagem, o conhecimento que geralmente se adquire assume conotações estáticas, fragmentadas, dissociadas em termos ideacionais ("Ver é algo que fazemos tanto com idéias quanto com sentidos"). "As pessoas que usam concepções diferentes ao abordar o mundo, vêem o mundo de forma diferente" - LAKATOS, 1970; TOULMIN, 1972 - isto quer dizer que "Não podemos ver o que não concebemos" - ARAGÃO, 1993). A visão contemporânea de Ciência implica conceber o conhecimento a ciência em termos representacionais de uma Ciência construída por indivíduos e grupos sociais, variando, portanto, em termos de conhecimento, de indivíduo para indivíduo, de sociedade para sociedade, mudando, assim, através dos tempos e em função de contextos sócio-históricos e culturais. E, mais ainda, surgindo da interação entre indivíduos e se constituindo efetivamente na interação social. Nesta perspectiva, tal visão implica tomar para si 
pensamentos relativistas, descartando o dogmatismo, a visão absolutista da ciência, o maniqueísmo usual das abordagens do ensino do certo e do errado - ensejando fragmentação de idéias e desconsideração do sujeito que produz/que ensina/que aprende... Tomar para si um pensamento relativista significa, portanto, assumir o "fim das certezas", redimensionar conceitos/concepções, cultivar dúvidas e admitir "erros" como aspectos imprescindíveis constitutivos do processo de aquisição de conhecimento. Isto quer dizer que os pontos nevrálgicos de uma outra (ou nova!) concepção redimensionada de Ciência - e historicamente contextualizada nos dias atuais - seja justamente o descarte dos atributos de verdade absoluta, inquestionável e imutável, que insiste na consideração da Ciência como pronta, acabada, definitiva. E, nesses termos, dada para ser aprendida sem qualquer participação interativa do sujeito que aprende.

C) Aspectos relativos à configuração de um paradigma emergente, em termos de uma concepção de Ciência que constitui "UM" dos desafios para os professores do século XXI.

Partimos, em termos escolares do ensino e da aprendizagem das ciências, de um paradigma científico moderno fundado nas Ciências Naturais (um "paradigma naturalístico" segundo SANTOS,1987.), para se chegar, no limiar do Terceiro Milênio, a um outro paradigma - considerado emergente! - de Produção Cultural Humana. Mesmo assim, a concepção escolar dogmática de ciência-verdade desconsidera qualquer espaço de discussão/debate, ou mesmo de inserção de dúvidas em relação ao dogmatismo científico, que possa ensejar entendimento/compreensão da trajetória da Ciência, no que diz respeito aos paradigmas de conhecimento (CHALMERS,1987) e, nessas relações cognitivas, termos chance de entender o contexto científico-tecnológico que estamos vivendo no presente (que já é futuro!). Isto ocorre, porque a ciência moderna sendo verdadeira é inquestionável, é a verdade que não se pode refutar, nem discordar. Nos termos de um paradigma emergente, diz-se que a ciência (pós-moderna?) é provisória. $\mathrm{O}$ atributo ou critério de inquestionabilidade dá lugar ao de provisoriedade e se passa a considerar seriamente a dinamicidade da produção do conhecimento científico-tecnológico em contraposição irreplicável a uma idéia de ciência taxativa, então permanente, da certeza, do "sempre foi assim"... Contudo, tais relações não se apresentam como inteligivelmente passíveis de assunção em âmbito escolar, mesmo que se passe a ter maior clareza das possibilidades de mudança em relação ao que já se conhece, de novas descobertas, do que de permanência reiterada do que já se conhece. É nestes termos que, no âmbito do ensino e da aprendizagem das ciências, todo conhecimento científico como auto-conhecimento - precisa ser tratado com cautela científica, isto é, como "aquilo que se conhece até agora”, em uma abertura clara de perspectiva ou de expectativa de mudança sustentável pela idéia de uma Ciência que progride, que evolui, que se desenvolve... portanto, admitindo "uma certa provisoriedade" construtiva.

\section{Obstáculos epistemológicos à supe-} ração da idéia de um único método científico no ensino de Ciências

Quando procuramos analisar a situação presente no Ensino das Ciências em seu conjunto, não podemos deixar de olhar para o passado, porque assim nos damos conta de que as descobertas ou os progressos científicos nos séculos que nos precederam e que, no dizer de SANTOS (1987), "não são mais que uma pré-história longínqua”, permaneceram quase inalterados ao nível escolar, mesmo nas salas de aula dos nossos dias (até mesmo a idéia de "terra plana"!). Isso, porque chegamos apenas a certos conhecimentos ditos científicos surgidos nos primeiros vinte anos do século $\mathrm{XX}$, para consideração do que precisa ser conhecido da Ciência em determinados níveis de escolaridade. Sendo assim, é possível dizer (também como SANTOS) que, em termos científicos, vivemos apenas no século XIX . 
Refletindo sobre descompassos como esses, parecem compreensíveis as razões pelas quais o método científico, usualmente ensinado nas escolas, assuma atributos tão estáticos na sua obsolescência, que hoje já podem ser considerados pseudocientíficos, mas, infelizmente, ainda continuam sendo reiterados na proposição deste método considerado único. Em qualquer nível de escolaridade, em qualquer grau de ensino, não se $\operatorname{trata}(\mathrm{m})$ de UM MÉTODO CIENTÍFICO ou de MÉTODOS CIENTÍFICOS, mas de O MÉTODO CIENTÍFICO claramente definido como "o único verdadeiro".

Tal método científico, único e verdadeiro, criado no âmbito da ciência dita moderna, desconfia da nossa experiência imediata, ao tomar como base do conhecimento científico a observação contraditoriamente descomprometida, livre, mas sistemática e rigorosa dos fenômenos naturais. O MÉTODO CIENTÍFICO exige o nãoenvolvimento do sujeito que observa, exige um sujeito isento, a salvo de qualquer contaminação/parcialização humana.

Nessa perspectiva, têm-se como conseqüências principais: a) a idéia de que conhecer é quantificar (rigor científico=rigor das medições), e b) o que não é quantificável, torna-se cientificamente irrelevante. É assim que o método científico se funda na redução da complexidade, posto que é, dissimuladamente, assumido em seu âmbito, talvez para justificar seu uso, que "o mundo é complicado, por isso a mente humana não pode compreendê-lo corretamente", daí a imprescindibilidade da adoção de formas mais simples ou simplificadas, embora reducionistas, para ensejar a "compreensão desejável". (Algum tempo depois, Bachelard afirmaria que, em termos de realidade, "o simples não existe, apenas existe o simplificado", o que é tornado simples, como na didática tradicional que "se simplifica para fins didáticos", para supostamente possibilitar a compreensão desejável sem "muita" complicação). É interessante assinalar que, nesse sentido, conhecer significa "dividir e classificar, para depois determinar relações sistemáticas (REGU.
LARIDADES) entre o que se separou". Assim, as leis da natureza são consideradas "o reino da simplicidade e da regularidade, onde é possível observar e medir com rigor", embora pouco importe se isso nada tenha de "natural" por ser "completamente arbitrário" (SANTOS, 1987: 15,16).

Um conhecimento baseado na formulação de leis tem como pressupostos: a) a idéia de ORDEM, b) a idéia de estabilidade do mundo e c) a idéia de que o passado se repete no futuro. Daí decorre a idéia de mundo-máquina, do mecanicismo/determinismo mecanicista que, como hipótese moderna, é uma forma de conhecimento utilitário e funcional, reconhecido pela capacidade de dominar e transformar, e não pela capacidade de compreender profundamente o real. Tais idéias, sustentáculos do único método científico, ganham corpo a partir do século XVIII e vão se constituir como pilares de uma outra idéia, a de progresso, que se consolida no positivismo oitocentista para o qual só há duas formas de conhecimento científico: 1) o conhecimento advindo das disciplinas formais da lógica e da matemática e 2) o conhecimento oriundo das ciências empíricas, segundo o modelo mecanicista das ciências naturais.

O ensino de Ciências, em qualquer nível de escolaridade, tem cultivado, sem alternativas, tal visão estática e historicamente descontextualizada (do presente) de método científico, quando poderia ser tão construtivo quanto educativo - na perspectiva de aquisição de conhecimento científico ao nível escolar - que, à medida que mergulhássemos no estudo de elaborações científicas e dos ideais de cientificidade, verificássemos descontinuidades e diferenças temporais entre teorias científicas como conseqüência não de uma forma mais evoluída, mais progressista ou melhor de fazer ciência, mas como resultado de diferentes maneiras de conhecer e construir objetos científicos, tanto de elaborar métodos quanto de inventar tecnologias (parafraseando CHAUÍ, 1998:257).

Essa descontinuidade no conhecimento científico levou o filósofo Bachelard (apud CHAUÍ, 
1998), na tentativa de explicar a necessidade de criação de novos modelos científicos, à criação da expressão "ruptura epistemológica" passível de relação significativa com "obstáculos epistemológicos". Para ele, os cientistas encontram obstáculos epistemológicos, quando os paradigmas existentes de conhecimento da Ciência não explicam resultados obtidos e nem levam aos resultados que se estão buscando.

Ao nível do ensino, tais obstáculos epistemológicos evidenciam-se também em função das abordagens tradicionais de ensino que se realizam sem levar em conta o sujeito que aprende, aquele que busca adquirir conhecimento. Se a ruptura epistemológica, segundo Bachelard, dá-se com a criação de novos (outros!) modelos científicos que afetam os atuais campos de conhecimento, os obstáculos epistemológicos surgem, além disso, do cultivo de idéias/representações que afetam justamente a natureza do sujeito, principalmente ao "des-asujeitá-lo", pela imposição de concepções/percepções externas que, por força da relação de poder aí estabelecida, o submetem à isenção. (Cada vez que se exige simples memorização de proposições científicas pelo sujeito que aprende, são criados obstáculos epistemológicos para aquisição/construção de conhecimento, pela ausência de sentido nas relações cognitivas que poderiam vir a ser compreensivamente estabelecidas).

Nesse caminho não-linear, contínuo e progressivo da Ciência, os obstáculos epistemológicos parecem residir no fato de que, à medida que progridem os conhecimentos que possuímos, mais e mais a Ciência é constituída de inferências e menos de fatos que não dependem, por exemplo, do princípio da autoridade para a aquisição de conhecimentos. Isto, porque a busca do conhecimento filosófico sobre as ciências (uma visão epistemológica), em relação aos obstáculos e limitações do método científico, tornou-se muito mais perceptível nos últimos anos deste século, fazendo com que os "ideais de cientificidade", desde a antiga concepção de
Ciência até a moderna (século XVII), possam dar lugar a problemas novos e a enunciados mais precisos e consentâneos a problemas antigos.

Em decorrência do cultivo dessas idéias, cultivam-se obstáculos epistemológicos - pela adoção de um único método científico - que ocasionam grandes perdas para o ensino e a aprendizagem das ciências. Tais perdas tornam-se perceptíveis, quando se explicitam e evidenciam os atributos sobremaneira estáticos ou estatizados e simplificados do método científico em termos referentes a "atributos de verdade, de unicidade, de inquestionabilidade, de definitivação, de quantificação e de imutabilidade do conhecimento". Daí decorrem, por sua vez, tanto os raciocínios casuísticos, fragmentários, quanto às concepções errôneas geralmente mantidas em suas reduções - mormente pela ausência de contrapontos de discussão - dada a existência de crenças sociais explícitas, dentre as quais, explicações de origem religiosa, mitos, tabus, preconceitos, que entram em conflito com explicações científicas aceitas na atualidade.

Na perspectiva de superação da idéia de um método científico único, digno de consideração no âmbito do ensino das ciências, há de se por em pauta a superação progressiva dos obstáculos epistemológicos já indiciados. Para tanto, tornase imprescindível assumirmos um outro ponto de vista para compreensão da Ciência, isto é, assumirmos uma visão relativista do conhecimento, admitindo uma certa provisoriedade na dinâmica das relações de processos científicos compreendidos em termos de produção cultural humana. Um pensamento relativista propicia dar atenção à diversidade, considerando extremos sem privilegiá-los. Aprender a relativizar é algo que deve fazer parte do processo educativo/formativo do cidadão, posto que qualquer situação/evento/ocorrência pode ser vista com pontos de vista diferentes, salvaguardados os pensamentos absolutistas.

Em suma, a assunção de um pensamento relativista pode significar a deflagração de um pensamento mobilizador propulsor de mudanças 
na concepção de Ciência e, mais ainda, na aceitação da existência de inúmeros e variados caminhos metodológicos que propiciem mudanças contínuas na realidade escolar/social, configurados como desafios para os professores do século XXI.

\section{Aspectos teóricos-metodológicos-} epistemológicos dos conteúdos do ensino de Ciências em uma relação triádica de inclusividade

Se, no âmbito dos processos de ensino das ciências, assumirmos como professores a visão de uma ciência externa/neutra/quantitativa/empírica, parece claro que assumiremos concomitantemente uma visão de sujeito correspondente ao que tal visão implica ou gera, como conseqüência, para o ensino e para a aprendizagem: uma visão de sujeito isento/neutro, capaz de absorver - em 'termos de aprendizagem' e de forma passiva - as informações/dados/fatos/percepções/concepções ditas científicas que lhe forem apresentadas "para serem aprendidas" na mesma forma da apresentação. Tais relações conceituais entre ciência/conhecimento e o sujeito-que-precisaconhecer, de modo geral, não se tornam facilmente perceptíveis, posto que a idéia dominante de sujeito, do ponto de vista docente, implica o que é aqui referido como "des-a-sujeitação", isto é, implica a descaracterização do sujeito em sua capacidade de assumir-se como gestor/produtor/construtor do seu próprio conhecimento.

Dito de outra forma, se um professor encarar a ciência como "a visão do verdadeiro, do definitivo, do certo", sem dúvida exigirá que o sujeito/aluno reproduza tal visão apresentando uma única resposta verdadeira/correta para qualquer questão que lhe vier a ser posta. Nesta relação, o científico é sempre algo taxativo, correto, inquestionável, exato, apresentado ou transmitido ao sujeito-que-aprende para ser memorizado (e se possível jamais esquecido). Trata-se - como é freqüente em âmbito escolar da visão linear, cumulativa de ciência imutável e inquestionável. Uma ciência de conteúdos prontos, definidos e definitivos, que são apenas dados de uma realidade ideal, simplificada, estática. Esta é a ciência geralmente presente e cultivada em âmbito escolar, em termos sobremaneira descontextualizados, quer dizer, em termos a-históricos, a-temporais; uma ciência fragmentária, dissociada do sujeito.

Numa perspectiva cartesiana do pensamento racional, encorajavam-se os indivíduos (não os sujeitos) a cultivarem a sua mente "racional", em detrimento do seu organismo total. A partir daí, criavam-se, efetivamente, e enfatizavam-se as dicotomias, os dualismos, cultivados até hoje: corpo/mente, matéria/espírito. A visão cartesiana de realidade valoriza, sobremaneira, o método científico e o pensamento racional (quantificar...classificar...) estimulando atitudes ditas "antiecológicas" no presente, posto que a natureza é vista como e torna-se um sistema mecânico para ser manipulado, explorado.

A assunção dessa visão mecanicista da ciência/do conhecimento - em cujo âmbito, para "compreender" a realidade, precisa-se dividi-la, reduzir suas partes para ensejar o conhecimento do todo - revela-se na maneira fragmentada de se abordar e lidar com a ciência/com o conhecimento em nível escolar, dividindo-o em disciplinas compartimentadas/isoladas, as quais se perpetuam sem qualquer tipo de interação cognitiva entre elas. Tal visão, cristalizada no ensino das ciências em nossas escolas brasileiras, continua, além disso, a estar presente, exercendo enorme influência em vários aspectos das nossas vidas, na nossa visão de mundo.

Em termos mais enfáticos, pode-se dizer que, por não sermos educados/ensinados a ver a nós próprios como sujeitos cognoscentes e agentes, por não termos consciência de nossa subjetividade como algo imbricado à nossa identidade/dignidade de ser humano, tendemos a ver a realidade, o mundo, com os olhos dos outros ou pelos olhos dos outros, de cientistas, de professores, de minorias privilegiadas... Mais ainda, além de sermos relegados "pedagogica- 
mente" à condição de passividade como "sujeitos" (quer na família, quer na escola), tanto subjugados pelo dever de obedecer quanto pelo poder das verdades científicas, temos permanecido não só passivos, mas inertes, desconfiados da nossa capacidade de 'ser sujeito', uma vez que nem sequer acreditamos na nossa capacidade de pensar...

Sendo assim, também a nossa capacidade de percepção da realidade fica comprometida de forma tal, que não somos capazes de fazer inferências a partir da realidade, nem mesmo de questioná-la, de tentar entendê-la, quanto mais de transformá-la. Se não vemos motivos, nem nos dão razão para compreendê-la, também não parece valer a pena fazer qualquer esforço para explicá-la. Aprendemos a desenvolver, no entanto, uma crença cega na ciência, buscando orientar a nossa vida em sociedade a partir de suas descobertas e orientações, principalmente quando materializadas ao nível tecnológico (ou descartamo-la como mecanismo de defesa). Isto tudo, porque, como assinala CHALMERS, 1993:18), a alta estima pela Ciência não está restrita à vida cotidiana e à mídia popular. É evidente no mundo escolar e acadêmico e em todas as partes da indústria do conhecimento.

Desde seus primórdios, no século XVI, a ciência moderna descarta a subjetivação como algo pernicioso. A esse respeito, MORAES (1997:33) explica que, para o homem medieval, a realidade era sagrada por ter sido estabelecida por Deus e cabia ao homem contemplar e compreender a harmonia existente no universo. Dessa forma, o paradigma vigente, representando o pensamento medieval, chegava a impedir o avanço do conhecimento e, por sua vez, da humanidade, uma vez que a realidade era vista (como ainda hoje em certo sentido na escola) como algo dado, pronto, acabado, cabendo ao homem apenas adequar-se a ela e contemplar a obra de Deus. E mais, todos aqueles que ousavam questionar a concepção de mundo vigente eram severamente punidos, condenados por heresia.

Por razões como essas, a ciência moderna traz a marca da objetividade e da fragmentação do conhecimento, dissimulando o sujeito ou concebendo-o isento. Ao constituir-se sob o domínio das ciências naturais, alijando o sujeito, a ciência distanciou-se de outros campos de conhecimento, por exemplo, das ciências sociais ou humanas, sob o argumento da "falta de racionalidade", posto que essas não conseguiam (e não podiam!) se ajustar aos mesmos princípios epistemológicos, aos mesmos métodos de investigação, e até aos mesmos critérios (rigor, isenção, objetividade...) adotados nas ciências naturais (SANTOS, 1997).

Contudo, com o passar do tempo (jamais considerado pela escola), lançaram-se, nos séculos subseqüentes, novas possibilidades de explicação da realidade, até os nossos dias, quando passamos a ter novas visões/concepções que se configuram como contribuições apresentadas em termos bastante contundentes, principalmente na segunda metade deste século XX e em culturas dominadas pela ciência, na qual as possibilidades de transformação só são aceitas se (pelo menos aparentemente) tiverem bases científicas. Chega-se a admitir/assumir, portanto, como diz CAPRA(1982), que o pensamento científico não tem que ser necessariamente reducionista e mecanicista, posto que as concepções holísticas e ecológicas também são cientificamente válidas. (...) As teorias científicas não estarão nunca aptas a fornecer uma descrição completa e definitiva da realidade. Serão sempre aproximações da verdadeira natureza das coisas. Tais contribuições, em contraposição, embora não tenham merecido consideração escolar no ensino e na aprendizagem, são valiosas, pois se apresentam como se nos tivesse sendo dada a "chave da cadeia", para desencarceramento da nossa mente de uma visão de mundo reduzida e limitada exclusivamente às explicações científicas no estrito sentido cartesiano.

Ensinar a olhar a realidade, a partir do que nos alerta CAPRA - como representante de um novo ponto de vista da ciência e de cientistas -, leva-nos a reconhecer que o conhecimento científico, que vale ser tratado no ensino e na 
aprendizagem escolar, precisa deixar de ser considerado pronto e acabado, bem como precisa deixar de ser tido como absolutamente verdadeiro. Isto, porque, ANTES DE TUDO, torna-se educativo/construtivo/formativo poder reconhecer seus atributos de dinamicidade, de provisoriedade, para retirá-lo da condição usual de verdade absoluta. Passa-se a ter, assim, a partir dessa outra visão, a possibilidade de questioná-lo, criticá-lo, de tentar entendê-lo e até de refutá-lo em seus vários aspectos. Temos, portanto, a possibilidade de não mais deixar aprisionar a nossa mente pela imposição/ aceitação de uma única (e verdadeira!) explicação dita científica, mas, diferentemente de tal unicidade de idéias, considerar as várias explicações possíveis/acessíveis.

É nesta perspectiva que se põem os aspectos atinentes à consideração do sujeito que busca conhecer fora do âmbito de cultivo das dicotomias que se tornaram características deste século XX, dentre as quais conteúdo-forma, teoriaprática e que geraram, por sua vez, em contextos como o nosso, outras dicotomias, dentre as quais a referente ao pedagógico-específico na consideração do conhecimento/conteúdo de ensino no curso da formação de professores e da abordagem/do desenvolvimento de processos de ensino. Tais dicotomias, como parece possível entender, advêm da ruptura do sujeito, porque, concebido como aquele que produz, mas, ao mesmo tempo, tendo de postar-se como "isento", tem de "assimilar" ("tornar semelhante a si ?") o que não lhe diz respeito de forma "compreensiva", segundo a determinação de outrem, um cientista ou seu professor.

Se é assim, explicita-se, dentre possibilidades de superação (ou de ultrapassagem) de dicotomias, como as mencionadas, a relação aqui referida, de acordo com ARAGÃO (1998), como triádica de inclusividade, a qual implica a tomada/retomada da construção da subjetividade, no sentido de requerer para o âmbito processual escolar, no ensino e na aprendizagem, a ajuda pedagógica imprescindível a cada aluno(a), para que ele (ela) possa assumir-se, progressivamente, como sujeito de suas ações frente à possibilidade de criar/recriar o mundo em que vive, para que ele(ela) venha a sentir-se capaz de desenvolver reflexões sobre si próprio, suas idéias ou pensamentos, sobre a ciência, o ponto de vista científico, e as relações ciênciasociedade (ARAGÃO, 1998:1).

Nestes termos, imbricam-se os aspectos teóricos-metodológicos-epistemológicos, ao se tornarem pedagogicamente disponíveis os conteúdos do ensino de ciências, posto que é, a partir da compreensão de relações cognitivas ou do estabelecimento de relações compreensivas entre idéias (geralmente presentes nesses conteúdos) na interação em aula, no curso do processo de ensino e de aprendizagem, que se institui o espaço necessário à construção da subjetividade do aluno, no âmbito das Ciências e de qualquer outro campo de saber. Se eu compreendo, se estabeleço relações entre conteúdos, informações, procedimentos, torno-me capaz de atribuir valor, de construir valores meus, de ser sujeito do meu conhecimento, das minhas ações. (ARAGÃO, 1998:3)

Se as dicotomias, deste ponto de vista, surgem da desconsideração ou, mais ainda, do esfacelamento do sujeito, é a busca de integração desse sujeito que pode auxiliar, como se disse, a ultrapassá-las. Para tanto, preciso - enquanto sujeito assumir a minha teoria e a minha prática , em função das teorias e das práticas a partir das quais, sobre as quais e nas quais reflito. Se aprendo a estabelecer relações cognitivas, passo a estabelecer relações de imbricação entre o que penso, o que elaboro, o que faço em função de conteúdos de ensino (conhecimento) e da minha possível autonomia como sujeito.

Nossa visão do real - mesmo ainda linear, simplificada - precisa ser progressivamente diferenciada, para aceitar "desordens" e considerar os vários aspectos que compõem nossa realidade. A respeito dessa visão simplificada de realidade ainda dominante em âmbito escolar - MORIN (1991) assinala que...se tentarmos pensar o fato de que somos seres simultaneamente físicos, biológicos, sociais, culturais, psíquicos e espirituais, é evidente 
que a complexidade reside no fato de se tentar conceber a articulação, a identidade e a diferença entre todos estes aspectos, enquanto o pensamento simplificador ou separa estes diferentes aspectos ou os unifica através de uma redução mutiladora.

Tendo em vista uma busca continuada, para chegarmos a lidar com essa complexidade, isto é, com a unidade na diversidade, pela compreensão de uma relação pedagógica em termos triádicos de inclusividade, buscamos o sentido da teoria da complexidade para a educação que é (também) pôr um fim nas certezas. Isto, porque é a aparente certeza das nossas convicções que nos impede justamente de perceber, como assevera ABREU JÚNIOR (1998), que o conhecimento está sempre se produzindo e se transformando. Nós mesmos estamos nos produzindo e nos transformando incessantemente.

\section{À guisa de conclusão : desafios para os professores do século XXI}

Os desafios que decorrem das discussões aqui travadas são postos para os professores das Ciências que estarão atuantes no século XXI, cuja referência temporal já não mais se põe em termos longínquos, posto que este século já se inicia no próximo ano de 2001. A referência secular que geralmente se põe como um futuro distante, é o agora. Independentemente de tal injunção temporal, contudo, não é possível considerar que os professores do futuro - que já é presente! - tenham que aceitar tais desafios por si sós e assumi-los por sua própria conta e risco, tornando-se responsáveis por "aquilo que não tiveram".

Muito embora costumemos ser veementes, incidindo sobre e exigindo qualidade pedagógica da ação docente, no ensino das Ciências, é preciso que vejamos sempre que os saltos qualitativos possíveis se põem em dependência ao tipo de formação/de desenvolvimento profissional que tais professores puderam ter, tanto em termos de sua formação primeira, a inicial, quanto em termos de sua formação continuada e desde que possa haver diferenciação qualitativa de uma, de outra, ou de ambas as oportunidades de formação. Sozinhos, certamente, todos nós continuaremos a pensar o que sempre se pensou da Ciência, bem como a fazer o que sempre foi feito.

\section{REFERÊNCIAS BIBLIOGRÁFICAS}

ARAGÃO, R.M.R.de. Ciência e Prática Pedagógica. Texto apresentado em Painel no IX ENDIPE, Águas de Lindóia, SP:1998.

CAPRA ,F. Ecologia Profunda, Um novo paradigma.In: Teia da Vida: A nova compreensão científica dos sistemas novos. São

Paulo: Cultrix,1997. O Ponto de Mutação. A ciência, a sociedade e a cultura emergente. São Paulo: Cultrix, 1982.

CHALMERS, A. F. O que é Ciência Afinal?. São Paulo: Brasiliense,1993.

CHAUÍ, M. Convite à Filosofia. São Paulo: Ática,1997.

LAKATOS, I. Falsification and the methodology of scientific research programmers. In: LAKATOS MUSGRAVE, A (Ed)

Criticism and the growth of knowledge. Cambridge:University Press, 1970.

MORIN, E. O desafio da complexidade. In: Ciência com Consciência. Lisboa: Publicações Europa, América,1991.

PRIGOGYNE, I., O Fim das Certezas: Tempo, Caos e as Leis da Natureza. São Paulo: UNESP, 1996.

SANTOS, B. de S. Um discurso sobre as Ciências. 9 ed. Porto: Afrontamento, 1997.

TOULMIN, S. Human Understanding. Princeton: Princeton University Press,1972. 